\title{
USING DIFFERENT ELECTRE METHODS IN STRATEGIC PLANNING IN THE PRESENCE OF HUMAN BEHAVIORAL RESISTANCE
}

\author{
A. S. MILANI, A. SHANIAN, AND C. EL-LAHHAM \\ Received 16 December 2005; Revised 26 June 2006; Accepted 24 July 2006
}

In the multicriteria strategic planning of an organization, management should often be aware of employees' resistance to change before making new decisions; otherwise, a chosen strategy, though technologically acceptable, may not be efficient in the long term. This paper, using a sample case study within an organization, shows how different versions of ELECTRE methods can be used in choosing efficient strategies that account for both human behavioral resistance and technical elements. The effect of resistance from each subsystem of the organization is studied to ensure the reliability of the chosen strategy. The comparison of results from a select number of compensatory and noncompensatory models (ELECTRE I, III, IV, IS; TOPSIS; SAW; MaxMin) suggests that when employee resistance is a decision factor in the multicriteria strategic planning problem, the models can yield low-resistance strategies; however, ELECTRE seems to show more reasonable sensitivity.

Copyright (c) 2006 A. S. Milani et al. This is an open access article distributed under the Creative Commons Attribution License, which permits unrestricted use, distribution, and reproduction in any medium, provided the original work is properly cited.

\section{Introduction}

Strategic planning in general aims at improving the competence of an organization regarding, for example, its technical abilities, management, and employee culture. One important yardstick for choosing efficient strategies, however, is human behavioral resistance within the organization. Human behavioral resistance is a natural response to a change because a change normally involves going from known to unknown [3]. There are a number of case studies (e.g., [19]) that show that employee resistance is the most frequent type of resistance encountered by managers during organizational changes. Example of such changes may be the restructuring and realigning of departments or divisions, major reorganization of systems and procedures, and the introduction of innovative process technologies [2]. If management focuses only on the technical elements of these 
changes, without taking into account the equally important human behavioral resistance element, it can crucially undermine the organizational efficiency [2].

On the other hand, since each individual and his/her perception of resistance is normally different from others, it would be desirable to combine individual behavioral resistances into an overall factor representing the resistance of a team, department, and eventually the whole organization. It is shown that overall indices in multiple criteria optimization methods can be employed to this end [9]. Once an overall resistance for different strategies is defined, it can be included as a new criterion (strategy resistance factor) next to other technical criteria in a decision matrix. Subsequently, choosing the proper strategy is reduced to solving a conventional discrete optimization problem using available multiple attribute decision-making (MADM) models.

There are essentially two different approaches for solving MADM problems: compensatory and noncompensatory. The main difference between the two is that in compensatory models explicit tradeoffs among attributes can be permitted. Compensatory MADM models have been based mainly on the multiattribute utility theory (MAUT) [8], where a single overall criterion is estimated and optimized, and therefore direct compensations between attributes may be allowed. Commonly used examples of MAUT or MAUT-related methods are SAW (simple additive weighting method) [8] and AHP (analytic hierarchy process) [16]. The noncompensatory MADM models are mainly based on comparisons of alternatives, which are made with respect to individual criteria. An example of the latter approach is the ELECTRE (ELimination Et Choix Traduisant la REalité) method [10]. While it is argued (e.g., [1]) that ELECTRE is principally noncompensatory, a few references (e.g., [6]) consider it as a partially compensatory submodel. What distinguishes ELECTRE from compensatory models such as SAW is the fact that the weights in ELECTRE are "coefficients of importance" (not criteria substitution rates) and, moreover, a very bad value on a criterion cannot be offset by good values on other criteria [7].

Nevertheless, in many strategic planning problems, there is no precise measure to select a correct model [7]. For a given problem, there are both compatibilities and incompatibilities using each model. In such situations, it is reasonable to examine different models, which normally yield different solutions, before making a final decision $[8,20]$. Each method emphasizes different aspects of the decision and a good choice can then be made among the alternatives suggested by the majority of the methods.

In [9], the TOPSIS (technique of ranking preferences by similarity to the ideal solution) compensatory method [6] is discussed and employed to solve a multicriteria strategic planning problem of a local gas company in the presence of its complex employee resistance structure. This paper, using different versions of the ELECTRE methods, examines the outranking approach to solve the same problem. The results are compared to TOPSIS as well as to a fully compensatory (SAW) and a fully noncompensatory method (MaxMin) to verify the effect of compensations and noncompensations in the methods and their sensitivity to the human resistance factor. It is of particular interest to see how different approaches of the MADM models differ from each other when employee resistance is a critical factor in the problem. The effect of individual subsystem resistances in the organization is also studied to ensure the reliability of the chosen strategy by ELECTRE. 
The rest of this article is organized as follows. Section 2 briefly reviews principles of the ELECTRE methods as well as their similarities and differences. A comparison of the outranking approach in ELECTRE with the one used in the MUAT or MAUT-like models is also presented in this section. Section 3 gives a summary of the proposed sample case study. Section 4 uses a select number of ELECTRE methods to solve the strategic planning problem of an organization. In this section, results are discussed and compared to different MADM approaches. In Section 5, a comparative sensitivity analysis is carried out with respect to the human behavioral resistance factor. Finally, the concluding remarks are presented in Section 6.

\section{Principles of ELECTRE methods}

The original ELECTRE approach has first appeared in [10]. A typical MADM problem that the method aims to solve consists of

(i) $m$ alternatives $M_{i}, i=1, \ldots, m$;

(ii) $n$ criteria $g_{j}, j=1, \ldots, n$;

(iii) $n$ weighting factors $\omega_{j}, j=1, \ldots, n$, normally, $\sum_{j=1}^{n} \omega_{j}=1$.

The goal is then to select the best alternative given the performance values of each alternative with respect to each criterion (given as an $m \times n$ decision matrix) and the corresponding weights of the criteria. For modeling the preference information between each pair of alternatives, such as $M_{i}$ and $M_{k}(i, k=1, \ldots, m)$, ELECTRE uses the concept of outranking relations. A true outranking relation of $M_{i} \rightarrow M_{k}$ (also denoted as $M_{i} S M_{k}$ ) implies that $M_{i}$ is preferred to $M_{k}$ if $M_{i}$ is at least as good as $M_{k}$ on a majority of criteria and if it is not significantly bad on any other criteria (i.e., the difference between the two are within a predefined threshold) [4]. By establishing such a relation between each and every pair of alternatives, one can then eliminate the dominated alternatives and arrive at the nondominated solutions. The construction of the outranking relations, however, is not an unambiguous task, particularly in the presence of conflicting multiple criteria. Furthermore, there are cases where the given values in the decision matrix are not crisp (e.g., due to uncertainty in the data).

The identification of an outranking relation between $M_{i}$ and $M_{k}$ requires two sets of comparisons: one among the criteria in which $g_{j}\left(M_{i}\right)$ is superior to $g_{j}\left(M_{k}\right)$, one among the criteria in which $g_{j}\left(M_{i}\right)$ is not superior to $g_{j}\left(M_{k}\right)$. In other words, the ELECTRE methods need to separately examine both the criteria that vote for $M_{i} \rightarrow M_{k}$ and those that veto such relation. These two sets of comparisons are performed based on the socalled concordance and discordance tests.

The concordance test allows the decision maker (DM) to verify if $M_{i}$ is at least as good as $M_{k}$. In some of the ELECTRE methods (e.g., ELECTRE I and II [13]), such a test is binary in nature: the concordance index is 1 when the test is passed and it is 0 when the test is failed. For example, if the criterion $g_{j}$ is to be maximized, the condition $g_{j}\left(M_{i}\right)<$ $g_{j}\left(M_{k}\right)$ results in a failed concordance test, whereas the condition $g_{j}\left(M_{i}\right) \geq g_{j}\left(M_{k}\right)$ results in a passed test. Some other ELECTRE methods (e.g., ELECTRE III [11], IV [5], and IS [15]) use a fuzzy outranking relation and pseudocriteria (described in Section 2.2), where the concordance index can take values between 0 and 1, depending on how far $g_{j}\left(M_{i}\right)$ is better than $g_{j}\left(M_{k}\right)$. 
The other extremity of the concordance test is the discordance test. It checks if there exists a very high opposition to the outranking relation $M_{i} S M_{k}$. This test is intended for the criteria in which $M_{i}$ performs worse than $M_{k}$, and it can be binary or fuzzy. If the test fails, it can be said that there is a high opposition vetoing the concordance test. For instance, if an alternative has the best values regarding some criteria but at the same time it has significantly low values regarding some other criteria, it is likely that it passes the concordance test but not the discordance test [4]. Only when both the concordance and discordance tests are passed, it can then be said that the outranking relation of $M_{i} S M_{k}$ is true. If neither $M_{i} S M_{k}$ nor $M_{k} S M_{i}$, then $M_{i} R M_{k}$, meaning that $M_{i}$ is incomparable to $M_{k}$. When $M_{i}$ is indifferent to $M_{k}$, it is said $M_{i} I M_{k}$, implying that one is not preferred over another for the DM.

In the following a brief description of solution procedures in different ELECTRE methods is presented. Detailed operations of each method can be found in references such as $[5,11,12,14,15,17,20]$. Here the goal is to point out the main similarities and differences in the solution mechanisms. Generally speaking, ELECTRE I and IS are designed for selection problems, whereas ELECTRE II, III, and IV are used for ranking problems [14]. Regardless, it is intended to examine how the different solution mechanisms of each method would affect the top rank solutions (here strategies) in the presence of human behavioral resistance in a strategic planning problem. This is part of the motivation for the case study presented in Section 3.

2.1. ELECTRE I. A concordance and discordance index set is first defined for each and every pair of alternatives $M_{i}$ and $M_{k}, i, k=1, \ldots, m, i \neq k$ (note that an alternative is not compared to itself):

$$
\begin{aligned}
& \text { concordance index set }=J_{i k}^{+}=\left\{j \mid r_{i j} \geq r_{k j}\right\}, \\
& \text { discordance index set }=J_{i k}^{-}=\left\{j \mid r_{i j}<r_{k j}\right\},
\end{aligned}
$$

$r_{i j}$ refers to a component of the decision matrix with the $i$ th alternative and the $j$ th criterion. Second, for each pair, the DM's weights for the corresponding concordance set are summed to arrive at a global concordance index, $C_{i k}\left(0 \leq C_{i k} \leq 1\right)$,

$$
C_{i k}=\frac{\sum_{j \in J_{i k}^{+}} \omega_{j}}{\sum_{j=1}^{n} \omega_{j}} .
$$

Similarly, a global discordance index for each pair of alternatives is defined, $D_{i k}\left(0 \leq D_{i k} \leq\right.$ 1),

$$
D_{i k}=\frac{\max _{j \in J_{i k}^{-}}\left|\omega_{j}\left(r_{i j}-r_{k j}\right)\right|}{\max _{j \in\{1, \ldots, n\}}\left|\omega_{j}\left(r_{i j}-r_{k j}\right)\right|} .
$$

Next, a global concordance threshold, $c$, and a global discordance threshold, $d$, are chosen to perform the global concordance and discordance tests. The more severe the threshold values, the more difficult it is to pass the tests (normally, $c=0.7$ and $d=0.3[4]$ ). For an outranking relation to be judged as true, both global indices should not violate their corresponding thresholds. That is, $C_{i k} \geq c$ and $D_{i k} \leq d$. Once the two tests are completed 
for all pairs of alternatives, the preferred alternatives are those that outrank more than being outranked.

Remark 2.1. To facilitate the mathematical implementation of the method, in some references such as [6], a concordance and discordance Boolean matrix is used to convert the results of each global concordance and discordance test to zero and one. The alternatives are then ranked using a final concordance-discordance Boolean matrix, which is found by an element-to-element product of the concordance and discordance matrices.

2.1.1. A modified version of ELECTRE I. van Delft and Nijkamp [18] suggested that to avoid defining the threshold values in ELECTRE I, one may define for each alternative a net concordance index $\left(C_{i}=\sum_{k=1, k \neq i}^{m}\left(C_{i k}-C_{k i}\right), i=1, \ldots, m\right)$ and/or a net discordance index $\left(D_{i}=\sum_{k=1, k \neq i}^{m}\left(D_{i k}-D_{k i}\right), i=1, \ldots, m\right)$. The net concordance and discordance indices provide the DM with an effective numerical measure to sort all the alternatives from the best to the worst. Higher net concordance and lower net discordance values are always preferred.

2.2. ELECTRE IS. This method is quite similar to ELECTRE I except that pseudocriteria instead of true criteria are used. For the $j$ criterion, the pseudocriterion is a function in which the discrimination between two alternatives is characterized by two thresholds: the indifference threshold $q_{j}$ and the strict preference threshold $p_{j}\left(p_{j} \geq q_{j}\right)$. The indifference threshold may represent the minimum boundary of uncertainty in the given data, while the strict preference threshold may represent the maximum boundary of uncertainty. In comparing each two alternatives such as $M_{i}$ and $M_{k}$ with respect to the criterion $g_{j}$, depending on the difference between the two alternative performances (i.e., $g_{j}\left(M_{k}\right)-$ $\left.g_{j}\left(M_{i}\right)\right)$, the concordance index, $c_{j}\left(M_{i}, M_{k}\right)$, can take a value between 0 and 1 . Assuming that $g_{j}$ is to be maximized, the concordance index can be given by

$$
c_{j}\left(M_{i}, M_{k}\right)= \begin{cases}0 & p_{j}<g_{j}\left(M_{k}\right)-g_{j}\left(M_{i}\right), \\ \frac{g\left(M_{i}\right)+p_{j}-g\left(M_{k}\right)}{p_{j}-q_{j}} & q_{j}<g_{j}\left(M_{k}\right)-g_{j}\left(M_{i}\right) \leq p_{j}, \\ 1 & g_{j}\left(M_{k}\right)-g_{j}\left(M_{i}\right) \leq q_{j} .\end{cases}
$$

Then, similar to ELECTRE I, the concordance index values are aggregated in a global concordance index using the DM's weights: $C_{i k}=\sum_{j=1}^{n} \omega_{j} c_{j}\left(M_{i}, M_{k}\right) / \sum_{j=1}^{n} \omega_{j}$. The discordance indices remain binary ( 0 or 1$)$. The main advantage of the method is that it allows the DM to choose the decision parameters as intervals instead of fixed (true) values. It is worth noting that when $p_{j}=q_{j}$, a pseudocriterion becomes a true criterion.

2.3. ELECTRE II. The main difference between this method and ELECTRE I lies in defining two outranking relations instead of one: the strong outranking and the weak outranking. $M_{i}$ strongly outranks $M_{k}$ if the corresponding concordance test for examining $M_{i} S M_{k}$ is passed strongly and the discordance test is passed fairly, or when the concordance test is passed fairly and the discordance test is passed strongly. On the other hand, $M_{i}$ weakly outranks $M_{k}$ if the concordance test is passed weakly and the discordance 
test is passed fairly. Note that in this method, all criteria are true. The problem with this method is that it requires too many threshold parameters in order to define the above two types of outranking relations. Namely, three global concordance thresholds (two for strong outranking and one for weak outranking) and two discordance thresholds for each criterion should be defined [4]. The implementation of the method is rather complex but it does provide a powerful process for the final classification of alternatives based on the obtained outranking relations.

2.4. ELECTRE III. While this method uses the same principles of ELCTRE II, it is similar to ELECTRE IS in that it uses pseudocriteria instead of classical true criteria. More precisely, for each criterion, an indifference threshold and a strict preference threshold are defined, each of which can be a constant or a function of the corresponding criterion value. Using these thresholds, the fuzzy presentations of the outranking relations are then possible. The main difference between this method and ELECTRE IS is in the fact that here both concordance and discordance indices are fuzzy (note that in ELECTRE IS the discordance index was binary). The discordance index in its fuzzy form is given as follows:

$$
d_{j}\left(M_{i}, M_{k}\right)= \begin{cases}0 & g_{j}\left(M_{k}\right)-g_{j}\left(M_{i}\right)<p_{j}, \\ \frac{g\left(M_{k}\right)-p_{j}-g\left(M_{i}\right)}{v_{j}-p_{j}} & p_{j} \leq g_{j}\left(M_{k}\right)-g_{j}\left(M_{i}\right) \leq v_{j}, \\ 1 & v_{j}<g_{j}\left(M_{k}\right)-g_{j}\left(M_{i}\right),\end{cases}
$$

where $v_{j}$ is called the veto threshold with respect to the $j$ th criterion $\left(v_{j} \geq p_{j} \geq q_{j}\right)$. Furthermore, instead of defining a global discordance index, in ELECTRE III an outranking credibility degree is defined by combining the discordance indices and the global concordance index with respect to a set of criteria for which the discordance index values are greater than the global concordance index value. Finally, similar to ELECTRE II, the classification of alternatives is performed using the obtained credibility degrees and a fuzzy outranking relation on ascending and descending distillation processes [4].

2.5. ELECTRE IV. In all aforementioned ELECTRE methods, the DM's weights are directly used in the calculation of global concordance indices. ELECTRE IV is currently the only version that does not require such weights. The method is similar to ELECTRE III: it uses different areas of preference to establish outranking relations. Depending on the magnitude of $g_{j}\left(M_{k}\right)-g_{j}\left(M_{i}\right)$, as compared to a set of predefined threshold values, the alternative $M_{i}$ can be strictly, weakly, and hardly preferred over the alternative $M_{k}$, or vice versa, or the two alternatives can be indifferent. The main difference is that in ELECTRE IV, instead of using a value of a membership function, the number of criteria in different preference areas is used. A set of credibility degrees similar to ELECTRE III is defined to classify the alternatives based on the ascending and descending distillation processes. The method can be particularly useful when the DM is not able to assign a set of preference weights to reflect specific requirements of a given decision-making problem. 
Remark 2.2. In some problems where the number of alternatives is large, the total number of necessary comparisons can rise drastically. In such cases, a new version of ELECTRE (termed ELECTRE TRI) can be used to reduce the computational cost of the method. This is done by introducing a few reference alternatives to which all the alternatives are compared $[4,5]$. In the case study chosen in this paper, the number of alternatives is small and thus this method is not considered.

Remark 2.3. The outranking approach in ELECTRE methods can be very different from the one used in the MAUT models where all criteria values are aggregated in a single evaluation value to rank all the alternatives. In the outranking methods, a bad performance of an alternative on one or more criteria is judged irrespective to its potential good performance on some other criteria. On the other hand, using the basic MAUT models such as SAW, the solution method is allowed to prefer an alternative that demonstrates a superior performance in the majority of criteria even though if it is very weak in the remaining criteria. There are other compensatory models, however, that are intended to limit this outcome by using ideal and nadir solution measures. The ideal solution is a referance optimal alternative whose criteria values are chosen to be the best of each column in a given decision matrix. In contrast, the nadir solution is an imaginary unfavorable alternative whose criteria values are chosen to be the worst of each column in a given decision matrix. A preferred alternative should be as close as possible to the ideal solution while it is far from the nadir solution [6]. A good example of these methods is TOPSIS. Generally speaking, the ideal and nadir solutions in TOPSIS are analogous to the concordance and discordance indices in ELECTRE. Accordingly, one may expect that for a given problem, the preferred strategies by TOPSIS and ELECTRE are normally in better agreement (particularly for problems with few criteria) than those by SAW and ELECETRE [20]. According to [20], SAW and ELECTRE may agree on the top-ranked alternatives.

\section{A multicriteria strategic planning case study}

Alfa is a local gas company that has encountered numerous complaints from its customers regarding its invoicing process. As a result, the management has decided to replace the current process with a more advanced and reliable one. Subsequently, a multiple-attribute decision-making problem is established. Seven strategies (alternatives) for the introduction of the new process are suggested by the DM (shown in Figure 3.1).

Strategy 1 is the nil solution (i.e., the gas company continues with its old invoice system). Strategy 2 says that the company searches to purchase, for example, a suitable commercial software to use it directly for the new invoice system. Strategy 3 says that the company employees design and implement a new (moderate-level) software themselves. Strategy 4 is the same as strategy 3 but with a very high technological quality. Strategy 5 says that the company buys a commercially available software and then does some modifications for a better implementation. Strategy 6 says that the company outsources to an external company to take care of the whole process of design, modification, and implementation of the new system. Strategy 7 is the same as strategy 6 but with a high technological quality. Of course the first and last strategies are two extremes and are expected 


\begin{tabular}{|c|c|c|c|}
\hline \multirow{3}{*}{$\begin{array}{l}\text { Original criteria: } \\
\text { cost, time, quality, } \\
\text { durability, technology }\end{array}$} & & & \multirow{6}{*}{$\begin{array}{l}\text { Strategies (alternatives): } \\
\text { 1: No change } \\
\text { 2: ERP is used in the company } \\
\text { 3: Experts in the company } \\
\text { perform IT project } \\
\text { 4: Experts in the company } \\
\text { perform IT project } \\
\text { with high technology }\end{array}$} \\
\hline & \multicolumn{2}{|c|}{ Final decision matrix } & \\
\hline & & \multirow{4}{*}{$\begin{array}{l}\text { Strategy } \\
\text { resistance } \\
\text { factors }\end{array}$} & \\
\hline \multirow{2}{*}{$\begin{array}{c}\text { Expected importance } \\
\text { of criteria } \\
\text { to subsystems }\end{array}$} & \multirow{3}{*}{$\begin{array}{l}\text { Criteria } \\
\text { weights }\end{array}$} & & \\
\hline & & & \\
\hline \multirow{3}{*}{$\begin{array}{l}\text { Subsystems: } \\
\text { systems department, } \\
\text { users, customer service, } \\
\text { management, } \\
\text { finance department }\end{array}$} & & & \\
\hline & \multicolumn{2}{|c|}{$\begin{array}{l}\text { Organizational } \\
\text { resistance matrix }\end{array}$} & \multirow{3}{*}{$\begin{array}{l}\text { 5: ERP is modified } \\
\text { and implemented by } \\
\text { experts in the company } \\
6 \text { : Experts external to } \\
\text { the company perform ERP } \\
7: \text { Experts external to } \\
\text { the company perform IT } \\
\text { project with high technology }\end{array}$} \\
\hline & & & \\
\hline $\begin{array}{l}\text { Overall influence and } \\
\text { resistance values }\end{array}$ & & & \\
\hline
\end{tabular}

(ERP: enterprise resource planning; IT: information technology)

Figure 3.1. A sample strategic planning problem in presence of organizational resistance.

Table 3.1. Criteria importance and system analysis for the information technology project.

\begin{tabular}{|c|c|c|c|c|c|c|c|c|}
\hline \multirow{2}{*}{ No. } & \multirow{2}{*}{ lbsystem } & \multirow{2}{*}{$\begin{array}{l}\text { Overall } \\
\text { influence }\end{array}$} & \multicolumn{5}{|c|}{ Expected importance of criteria to subsystems } & \multirow{2}{*}{$\begin{array}{l}\text { Subsystem } \\
\text { resistance }\end{array}$} \\
\hline & & & Technology & Time & Durability & & Cost & \\
\hline & department & ( & ( & $(3$ & $(7$ & $\begin{array}{c}\text { Average } \\
(4)\end{array}$ & $\begin{array}{l}\text { Very lov } \\
\text { (1) }\end{array}$ & \\
\hline & $\mathrm{u}$ & ( & $\mathrm{Lc}$ & $\begin{array}{l}\text { High } \\
(7)\end{array}$ & $\begin{array}{c}\text { Average } \\
(6)\end{array}$ & $\begin{array}{c}\text { Very high } \\
\text { (9) }\end{array}$ & $\begin{array}{c}\text { Very low } \\
\text { (1) }\end{array}$ & ge \\
\hline & Cust & $\begin{array}{l}\text { High } \\
(7)\end{array}$ & (1 & $\begin{array}{r}\text { Very } 1 \\
\quad(10\end{array}$ & $\begin{array}{r}\text { Aver } \\
(5\end{array}$ & $\begin{array}{r}\mathrm{Hi} \\
(7\end{array}$ & $\begin{array}{c}\text { Very low } \\
\text { (1) }\end{array}$ & ( \\
\hline 4 & it & $\begin{array}{l}\text { Very } \\
\quad(10\end{array}$ & Very low & $\begin{array}{r}\text { Very } \\
(1\end{array}$ & $\begin{array}{l}\text { High } \\
(7)\end{array}$ & $\begin{array}{l}\text { High } \\
(7)\end{array}$ & $\begin{array}{l}\text { High } \\
(7)\end{array}$ & Average \\
\hline & thes & $\begin{array}{c}\text { Very high } \\
(9)\end{array}$ & $\begin{array}{l}\text { Very high } \\
\text { (10) }\end{array}$ & $\begin{array}{c}\text { Very low } \\
\text { (1) }\end{array}$ & $\begin{array}{c}\text { Average } \\
(4)\end{array}$ & $\begin{array}{c}\text { Average } \\
(4)\end{array}$ & $\begin{array}{c}\text { Average } \\
(5)\end{array}$ & $\begin{array}{c}\text { Very high } \\
\text { (10) }\end{array}$ \\
\hline
\end{tabular}

to be highly resisted by some company employees. It should be noted that at the current state of the organization, all employees believe that a new invoice system is necessary.

The organization has been divided into five main subsystems; namely, a systems department, users, customer service, management, and a finance department. Based on the 
suggestions from these subsystems, five original criteria for the new process are chosen: cost, implementation time, quality, durability, and technology. It should be noted that quality, durability, and technology resemble benefit criteria (i.e., the higher the better) whereas time and cost resemble the opposite (i.e., the lower the better). As shown in Figure 3.1, each subsystem is linked to these criteria through its expected importance values. In addition, each subsystem has its own overall influence and resistance in the organization's hierarchy. The above values are considered as inputs of the problem (Table 3.1) and quantified by means of a 10-point scale of linguistic variables (very low, low, etc.).

The resistance values in Table 3.1 connote to which degree changes in expectations can be tolerated by subsystems, as opposed to their original expectations. Each and every subsystem may have its own belief of what the new invoice system should bring to the organization; and, therefore, to arrive at a final compromised solution, the resistance values should be accounted for. For instance, the management, which has a great deal of influence in the company, desires that the new system solves the complaints of customers and the delay in payments as soon as possible and with reasonable cost. Yet, this subsystem appears to be rather flexible to possible changes imposed by other subsystems (it has a moderate resistance level of 6). The customer service department, on the other hand, is mostly concerned about the time of project implementation; it is also very highly resistant to changes imposed by others. Note that the larger the resistance value is, the less flexible the subsystem is. As compared to other decision factors that are evaluated, based on performance elements of recommended strategies, what distinguishes the resistance notion may be its pure judgmental nature.

To parameterize employees' resistance with respect to the seven strategies, qualitative data was collected from each subsystem, forming a $7 \times 5$ organizational resistance matrix (Table 3.2). The decision maker's weights in this table are the normalized influence weights from Table 3.1. The entropy weighting method [6] is then used to define a revised weight for each criterion, which accounts for both the DM's weights as well as the contrasts in data sets (see [9] for more details). Next, by aggregating the individual resistance values in Table 3.2, an overall resistance factor for each strategy was defined for inclusion in the final decision matrix.

The final decision matrix is established by considering the seven possible strategies as being the alternatives and the cost, time, quality, durability, technology, and resistance factor as being the attributes. The data are collected as shown in Table 3.3. In this table, the decision maker's weights are obtained, using values of Table 3.1, by summing the influence weight of every subsystem multiplied by the expected importance value of each attribute. For example, for the cost criteria it can be written $\lambda_{\text {cost }}=\sum_{i=1}^{5} \lambda_{\text {subsystem }_{i}}^{\text {(influence) }} \times$ $\lambda_{\text {subsystem }_{i}}^{\text {cost }}$, where $\lambda$ denotes the DM's weight in general. It should be noted that the subsystem influence weights remain unchanged for all criteria. Similarly, for the resistance factor, the DM's weight can be found by summing each influence weight multiplied by the corresponding subsystem resistance (from Table 3.1). That is, $\lambda_{\text {resistance }}=\sum_{i=1}^{5} \lambda_{\text {subsystem }_{i}}^{\text {(influence) }} \times$ $\lambda_{\text {subsystem }_{i}}^{\text {resistance }}$. Finally, all weighting factors are normalized so that their summation is one.

Given the final decision matrix in Table 3.3, the next step is to use a select number of ELECTRE methods to choose a proper strategy for the organization. 
Table 3.2. The organizational resistance matrix with respect to strategies.

\begin{tabular}{l|ccccc}
\hline DM's weights & 0.138 & 0.138 & 0.194 & 0.277 & 0.253 \\
Revised weights & 0.209 & 0.119 & 0.180 & 0.257 & 0.235 \\
\hline \multirow{3}{*}{ Alternatives } & \multicolumn{5}{c}{ Subsystems $\rightarrow$} \\
& $\begin{array}{l}\text { Systems } \\
\text { department }\end{array}$ & Users & $\begin{array}{c}\text { Customer } \\
\text { service }\end{array}$ & Management & $\begin{array}{c}\text { Finance } \\
\text { department }\end{array}$ \\
\hline \multirow{2}{*}{ Strategy 1 } & Very high & Very high & Very high & Very high & Very high \\
& $(10)$ & $(10)$ & $(10)$ & $(9)$ & $(10)$ \\
Strategy 2 & High & Low & Very low & Very low & Low \\
& $(7)$ & $(3)$ & $(1)$ & $(1)$ & $(3)$ \\
Strategy 3 & Low & High & Very low & Very low & Very low \\
& $(3)$ & $(7)$ & $(1)$ & $(1)$ & $(1)$ \\
Strategy 4 & Very low & Average & Average & Average & Average \\
& $(1)$ & $(6)$ & $(5)$ & $(5)$ & $(6)$ \\
Strategy 5 & Low & Very Low & Low & Low & High \\
& $(3)$ & $(1)$ & $(3)$ & $(3)$ & $(7)$ \\
Strategy 6 & High & Low & Average & Average & Average \\
& $(7)$ & $(3)$ & $(6)$ & $(4)$ & $(4)$ \\
Strategy 7 & Very high & Average & High & High & Very low \\
& $(10)$ & $(4)$ & $(7)$ & $(7)$ & $(1)$ \\
\hline
\end{tabular}

Table 3.3. Given decision matrix and criteria weights.

\begin{tabular}{|c|c|c|c|c|c|c|}
\hline DM's weights & 0.108 & 0.187 & 0.181 & 0.165 & 0.128 & 0.231 \\
\hline Revised weights & 0.220 & 0.227 & 0.173 & 0.130 & 0.137 & 0.113 \\
\hline $\begin{array}{l}\text { Criteria } \rightarrow \\
\text { Alternatives }\end{array}$ & Cost & Time & Quality & Durability & Technology & $\begin{array}{l}\text { Strategy } \\
\text { resistance } \\
\text { factor }\end{array}$ \\
\hline Strategy 1 & $\begin{array}{c}\text { Very low } \\
\text { (1) }\end{array}$ & $\begin{array}{c}\text { Very low } \\
\text { (1) }\end{array}$ & $\begin{array}{c}\text { Very low } \\
\text { (1) }\end{array}$ & $\begin{array}{c}\text { Very low } \\
\text { (1) }\end{array}$ & $\begin{array}{c}\text { Very low } \\
\text { (1) }\end{array}$ & 0.635 \\
\hline Strategy 2 & $\begin{array}{l}\text { Low } \\
(3)\end{array}$ & $\begin{array}{c}\text { Very low } \\
\text { (1) }\end{array}$ & $\begin{array}{c}\text { Average } \\
\text { (5) }\end{array}$ & $\begin{array}{l}\text { High } \\
(7)\end{array}$ & $\begin{array}{c}\text { Average } \\
(4)\end{array}$ & 0.262 \\
\hline Strategy 3 & $\begin{array}{l}\text { High } \\
(7)\end{array}$ & $\begin{array}{l}\text { High } \\
(7)\end{array}$ & $\begin{array}{c}\text { Average } \\
\text { (5) }\end{array}$ & $\begin{array}{c}\text { Average } \\
\text { (5) }\end{array}$ & $\begin{array}{l}\text { Low } \\
(3)\end{array}$ & 0.204 \\
\hline Strategy 4 & $\begin{array}{l}\text { Very high } \\
\quad(9)\end{array}$ & $\begin{array}{c}\text { Average } \\
\text { (5) }\end{array}$ & $\begin{array}{l}\text { High } \\
(7)\end{array}$ & $\begin{array}{l}\text { High } \\
(7)\end{array}$ & $\begin{array}{c}\text { Average } \\
(6)\end{array}$ & 0.327 \\
\hline Strategy 5 & $\begin{array}{c}\text { Average } \\
(5)\end{array}$ & $\begin{array}{c}\text { Average } \\
(5)\end{array}$ & $\begin{array}{l}\text { Very high } \\
\text { (9) }\end{array}$ & $\begin{array}{l}\text { High } \\
(7)\end{array}$ & $\begin{array}{c}\text { Average } \\
\text { (5) }\end{array}$ & 0.297 \\
\hline Strategy 6 & $\begin{array}{l}\text { High } \\
(7)\end{array}$ & $\begin{array}{l}\text { Low } \\
(3)\end{array}$ & $\begin{array}{l}\text { High } \\
(7)\end{array}$ & $\begin{array}{l}\text { High } \\
(7)\end{array}$ & $\begin{array}{c}\text { High } \\
(7)\end{array}$ & 0.384 \\
\hline Strategy 7 & $\begin{array}{l}\text { Very high } \\
\quad(10)\end{array}$ & $\begin{array}{l}\text { Very high } \\
\text { (9) }\end{array}$ & $\begin{array}{l}\text { Very high } \\
\quad(10)\end{array}$ & $\begin{array}{l}\text { Very high } \\
\text { (9) }\end{array}$ & $\begin{array}{c}\text { Very high } \\
\text { (9) }\end{array}$ & 0.445 \\
\hline
\end{tabular}


A. S. Milani et al. 11

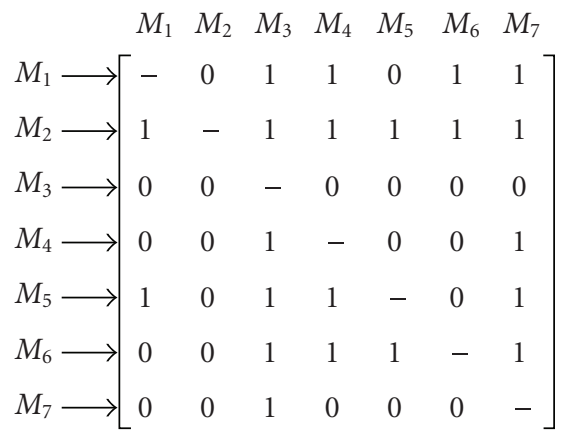

(a)

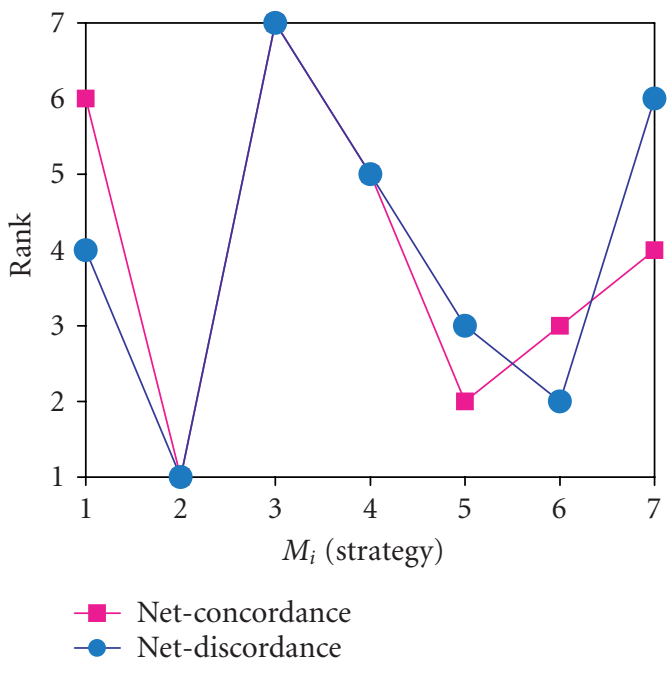

(b)

Figure 4.1. Results of ELECTRE I, net concordance and net discordance methods.

\section{Choosing a proper strategy}

The decision matrix of Table 3.3 is imported in a user-defined code in Mathematica 4.2 to solve the problem using ELECTRE I. The solution results are shown, for simplicity, in the form of a dominance matrix in Figure 4.1(a). This matrix gives the partial preference of the alternatives [6]. More precisely, each row shows whether or not $M_{i}$ dominates other alternatives (marked by 1 and 0 ), or conversely each column shows whether or not $M_{i}$ is dominated by other alternatives. Accordingly, strategy \#2 is selected as the best since it is not dominated by any other alternative and dominates all others (in this case, it can be said that strategy 2 is the only kernel member of the outranking relations), strategies $\# 1,5,6$ are comparable (i.e., they are equally favorable as the next option) it is worth noticing that $M_{1} S M_{6}$ and $M_{6} S M_{5}$, but $M_{1} \$ M_{5}$, indicating that the outranking relation is 


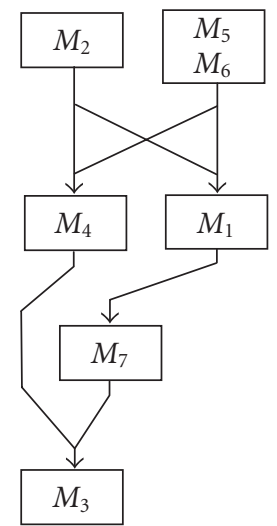

Figure 4.2. Classification results using ELECTRE III.

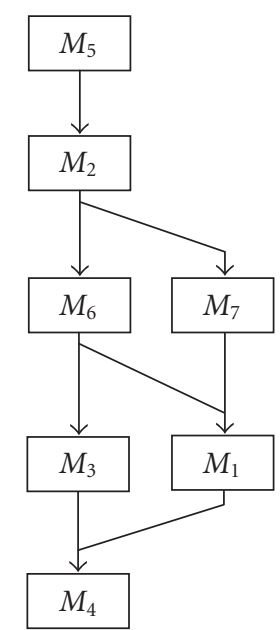

Figure 4.3. Classification results using ELECTRE IV.

not necessarily transitive [4]. Such intransitive loops may be removed before exploiting further outranking relations. Finally, strategies \#4, 7, 3 have the lower subsequent ranks. In order to rank each and every alternative, a modified version of the ELECTRE I method by van Delft and Nijkamp [18] is also incorporated into the same code, by calculating the net concordance and discordance values. As seen in Figure 4.1(b), the net concordance and discordance analyses also suggest that strategy \#2 is the most dominant and strategy \#3 is most dominated by other strategies (it has the worst rank). This is found despite the fact that strategy \#3 in Table 3.3 reveals the lowest organizational resistance. This outcome should be due to the fact that this strategy, apart from its low-resistance value, has relatively poor values in terms of the cost and time criteria; two criteria that are highly weighted in Table 3.3. 
A. S. Milani et al. 13

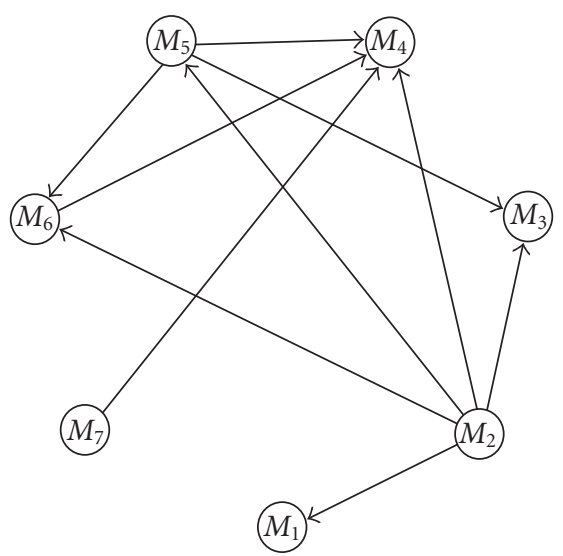

Figure 4.4. Outranking results using ELECTRE IS.

Table 4.1. Ascending and descending distillations in ELECTRE III and IV.

\begin{tabular}{c|cc|cc}
\hline Method & \multicolumn{2}{|c|}{ ELECTRE III } & \multicolumn{2}{c}{ ELECTRE IV } \\
\hline Strategy \# & $\begin{array}{c}\text { Descending } \\
\text { distillation }\end{array}$ & $\begin{array}{c}\text { Ascending } \\
\text { distillation }\end{array}$ & $\begin{array}{l}\text { Descending } \\
\text { distillation }\end{array}$ & $\begin{array}{c}\text { Ascending } \\
\text { distillation }\end{array}$ \\
\hline 1 & 4 & 1 & 5 & 3 \\
2 & 2 & 1 & 2 & 1 \\
3 & 4 & 6 & 4 & 4 \\
4 & 3 & 5 & 5 & 5 \\
5 & 1 & 2 & 1 & 1 \\
6 & 1 & 2 & 3 & 3 \\
7 & 4 & 4 & 5 & 3 \\
\hline
\end{tabular}

Next, the same problem is solved by the ELECTRE III, IV, and IS methods using the LAMSADE software [15]. The results obtained from these methods are shown in Figures 4.2, 4.3, 4.4, respectively. The final classifications of alternatives in ELECTRE III and IV are based on ascending and descending distillations (see, e.g., [4]) given in Table 4.1. In the final graphs, an arrow from alternative $M_{i}$ to alternative $M_{k}$ indicates that strategy $\# i$ dominates strategy $\# k$ in both descending and ascending distillations. Any two alternatives appearing in the same box are indifferent, and any two alternatives that are in disconnected boxes are incomparable. Based on ELECTRE III, strategy \#2 is incomparable to strategies \#5 and 6, but strategies \#5 and 6 are indifferent. Strategy \#3 (similar to ELECTRE I) is ranked as the last preferred strategy. Using ELECTRE IV, strategy \#5 receives the best rank, followed by strategy \#2, and strategy \#4 has the worst rank. Based on ELECTRE IS, the most frequently dominant strategy is strategy $\# 2$, followed by strategy \#5, while the most dominated strategy is strategy \#4. As a result, it can be said that according to different ELECTRE methods examined, strategies \#2 and 5 are good choices, with strategy \#2 having received the highest attention by the majority of the methods (namely, ELECTRE 
I, IS, and the net concordance and discordance analyses). In fact, the only method that explicitly outranks strategy $\# 5$ over strategy $\# 2$ is ELECTRE IV where the DM's weights are not taken into account [5].

The results for strategy \#1 may come as a surprise. Although this strategy implies that the organization should continue with its old invoicing process (i.e., no change made), none of the above methods considers strategy \# 1 as the worst solution. This should be due to the very low time and cost values required by this strategy (see Table 3.3), given that the two aforementioned criteria have the highest weights. Another observation that is worth mentioning from Figures 4.1-4.4 is that ELECTRE III, IV, and IS yield more incomparable and/or indifferent alternatives as compared to the other methods used. This may be expected because ELECTRE III, IV, and IS employ a fuzzy presentation of the criteria, and thus the concordance and discordance tests may not be as strictly decisive as in the crisp methods.

Remark 4.1. In Table 3.3, one notices that the strategy resistance factors are aggregated values from all subsystems of the organization. This means that, while management expects a chosen strategy with a general low organizational resistance, it can still have high resistance from a few particular subsystems. If the DM suspects that this may not be favorable, he/she can augment the decision matrix by considering the resistance of each subsystem as an individual criterion. As such, a chosen strategy is less likely to have very high resistance from a particular subsystem. For the present case, the latter augmentation results in a $7 \times 10$ decision matrix and yields the same chosen strategy (i.e., strategy $\# 2$ ).

4.1. Comparing with other methods. As addressed in Section 1, often there is no one and only one method for a given MADM problem. Therefore, it is worthwhile to examine different models from different categories.

The simplest and yet widely used method in the MAUT (sometimes called scoring) category of the compensatory MADM models is SAW, where an overall score for each alternative is found by summing the criteria values multiplied by their corresponding weights [6]. This method for the present case gives a ranking order of $(2,5,6,1,7,4,3)$ with the score set $(1.404,0.88,0.81,-0.078,-0.16,-0.20,-1.22)$, respectively. Note that in the SAW aggregation procedure, cost-like criteria are assigned negative values whereas benefit-like criteria have positive values. As compared to the results in Section 4, the top rank strategies by SAW are well comparable to those by the ELECTRE methods.

Another commonly used compensatory method is TOPSIS, which is also called a compromising submodel [6]. For the current case, study [9], using the ordinary TOPSIS method finds a ranking order of $(2,6,5,1,4,7,3)$ with the relative closeness to the ideal solution (TOPSIS index) as $(0.70,0.60,0.59,0.55,0.47,0.42,0.36)$, respectively. The TOPSIS index for strategies \#6,5,1 (i.e., 0.60, 0.59, 0.55) indicates that these strategies are comparable as is the case in ELECTRE I, whereas with SAW this is only true for strategies \#5 and 6.

The above observations generally support the results in [20], which uses a simulation comparison of select methods. Next, a noncompensatory model, namely, MaxMin is examined (see, e.g., [6]). In this method, after converting all criteria to the benefit-type and normalizing the decision matrix elements between 0 and 1 , the weakest performance 
Table 5.1. A comparison of rank orders based on the net value/score.

\begin{tabular}{l|cc}
\hline Method & Original case & $\begin{array}{l}\text { Case with an increased } \\
\text { resistance value }\end{array}$ \\
\hline Concordance analysis & $(2,5,6,7,4,1,3)$ & $(5,6,2,7,4,1,3)$ \\
Discordance analysis & $(2,6,5,1,4,7,3)$ & $(6,5,1,2,4,7,3)$ \\
TOPSIS & $(2,6,5,1,4,7,3)$ & $(6,2,5,1,4,7,3)$ \\
SAW & $(2,5,6,1,7,4,3)$ & $(2,5,6,1,7,4,3)$ \\
MaxMin & $(2,5,3-6,4,7-1)$ & $(5,2,3-6,4,7-1)$ \\
\hline
\end{tabular}

value of each alternative is to be maximized. Therefore, using this method, it is possible that an alternative is rejected because of its worst performance value on one particular criterion even though it has very good values with respect to other criteria. For the given case, the MaxMin method results in the ranking order $(2,5,6-3,4,7-1)$. In contrast to TOPSIS, SAW, and ELECTRE, the purely noncompensatory MaxMin method takes strategy \#1 (i.e., no change in the company) as the last option because it has the lowest quality, durability, technology and the highest resistance values (see Table 3.3) even though it demonstrates the lowest cost and time values. Furthermore, it can be seen that strategy \#3 that was chosen as the worst option by the SAW, TOPSIS, and some ELECTRE methods is considered as a moderate strategy by the MaxMin method. This is perhaps because strategy \#3 does not include any extreme bad values (i.e., 1 or 10 for the benefit-like and the cost-like criteria, resp.). Other methods consider this as one of the worst solutions perhaps because it does not include any superior values either.

\section{Sensitivity to the resistance factor and rank reversals}

The intent of this section is to verify the sensitivity of the above MADM methods to an unexpected change (beyond admissible variability defined by thresholds) in a criterion value for a strategy, and also to verify if any rank reversals occur due to this change. Here, for example, the resistance criterion value of strategy \#2 in Table 3.3 is increased by a factor of 5, and the new resistance column is normalized again so that the summation of the column is one. This may be useful if management decides to examine if there will be a change in the chosen strategy, should employee resistance increase dramatically in the long term, for example, due to unexpected complexities at the implementation stage. The new MADM problem is solved using all the methods that were used before. The ranking orders obtained for TOPSIS, SAW, MaxMin, net concordance and discordance analyses are given in Table 5.1. When compared to the original case, in the new case, SAW still selects strategy \#2 despite its significant increase in employee resistance, the TOPSIS and MaxMin methods slightly lower the rank of strategy \#2 without changing the order of other alternatives, and the net concordance and discordance methods place strategy 2 at the third and forth ranks, respectively. The latter may suggest that, for the given case, outranking methods can be more sensitive to significant changes in a criterion value (here the resistance value), and provide more dominant solutions. 


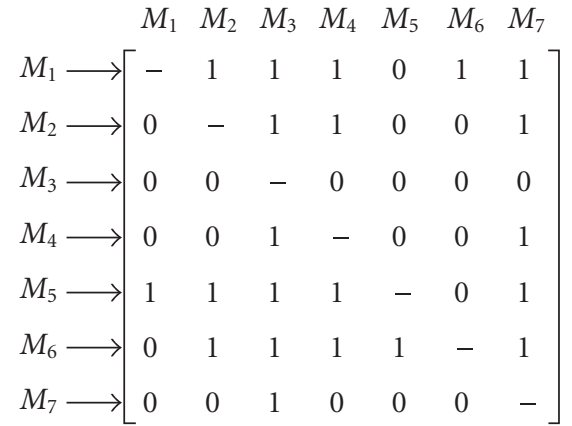

(a)

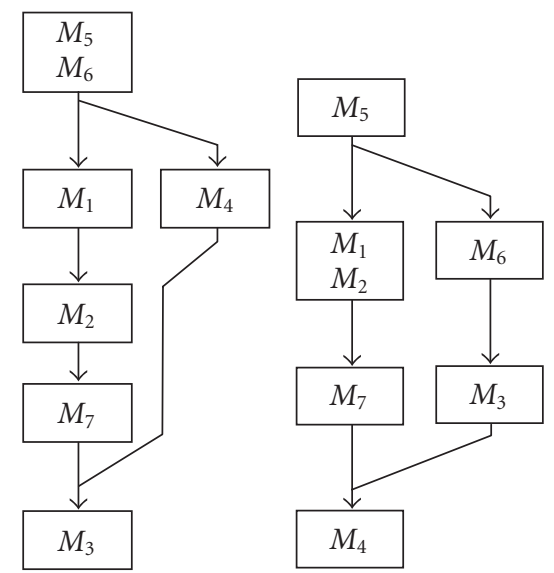

(b)

(c)

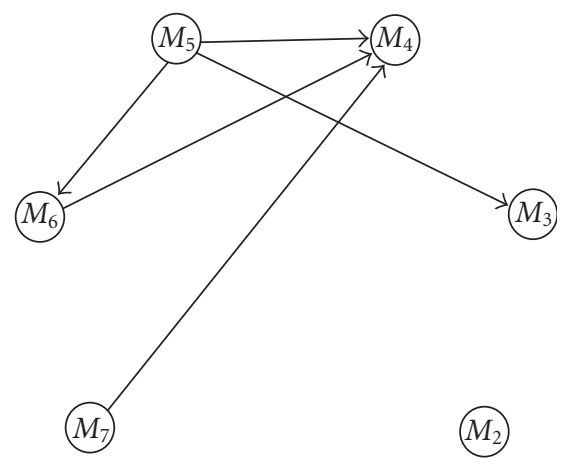

(M)

(d)

Figure 5.1. Results for the new case with an increased resistance factor. (a) ELECTRE I, (b) ELECTRE III, (c) ELECTRE IV (c), (d) ELECTRE IS.

To verify this further, results of the different versions of the ELECTRE method are obtained for the new case (Figure 5.1). For ELECTRE I, Figure 5.1(a) reveals that increasing the resistance factor causes strategy \#2 to be dominated by strategies \#5,6,1 (see the 1 values in the second column of the matrix). Also, from a comparison of dominance matrices in Figures 4.1(a) and 5.1(a), it is noticed that changing a criterion value in strategy \#2 has not changed the outranking structure for other alternatives (i.e., all the rows and columns remained unchanged except for those of strategy \#2). Similar arguments can be made for ELECTRE III and IS by comparing Figure 4.2 to Figure 5.1(b) and Figure 4.4 to Figure 5.1(d), respectively. ELECTRE IS shows higher sensitivity by removing all dominations of strategy \#2, making it completely incomparable. ELECTRE IV produces an 
indifferent solution (strategy \#1) and an incomparable solution (strategy \#6) for strategy $\# 2$, but it is the only method that causes restructuring of the outranking relations (compare Figures 4.3 and 5.1(c)). Such restructuring has caused rank reversals (e.g., between strategies \#1, 7), and may or may not be meaningful for the DM. It is believed that such rank reversals may occur when some thresholds or parameters of the decision process are allowed to be a function of criteria/alternatives. Further study in this regard may be worthwhile.

\section{Concluding remarks}

(i) It is shown that different ELECTRE methods can be used successfully in the strategic planning of an organization in the presence of human behavioral resistance. For the sample case studied, all ELECTRE methods resulted in a technically reasonable strategy with low employee resistance.

(ii) It is found that similar top-ranked solutions by ELECTRE are obtained by SAW as well as by ordinary TOPSIS. However, ELECTRE and TOPSIS are generally in better agreement than ELECTRE and SAW.

(iii) The noncompensatory MaxMin method may be considered only when the DM would like to avoid extremely bad criteria values in a chosen strategy; otherwise, it can undermine alternatives with very good performance values and thus the method should be used with discretion.

(iv) Unlike the compensatory methods used, an advantage of ELECTRE methods is that a significantly weak criterion value of an alternative cannot directly be compensated for by other good criteria values. On the other hand, the solution mechanism in ELECTRE methods is not as extreme as purely noncompensatory methods such as MaxMin.

(v) In general, ELECTRE I and IS suffice to determine the top-rank strategies. The presentation of pseudocriteria in the ELECTRE III, IV, and IS methods facilitates dealing with uncertain and qualitative data. ELECTRE III and IV can specifically be used for classification of alternatives. The net concordance and discordance methods are recommended when the strategies need to be sorted from best to worst, with no interest in indifference and incomparability relations.

(vi) In the present case study, the sensitivity of the ELECTRE methods to an unexpected increase in the resistance value of an alternative seems to be reasonable, by providing more dominant solutions over that alternative. The majority of the ELECTRE methods did not change the outranking structure among other alternatives, except for ELECTRE IV where some rank reversals in the studied case were observed. Such rank reversals in ELECTRE methods deserve further study.

(vii) ELECTRE III may be the most suitable method for applications similar to the one studied in this paper, because it can simultaneously account for (a) the DM's preference weights, (b) uncertainty in data with respect to both concordance and discordance tests, and (c) indifferent and incomparable relations among alternatives. Additionally, it seems to be reasonably sensitive to an unexpected change in the resistance criterion value. 


\section{Acknowledgments}

The authors would like to thank the anonymous referees for their constructive comments. The research of the first author is supported by the Natural Sciences and Engineering Research Council of Canada (NSERC).

\section{References}

[1] D. Bouyssou, Some remarks on the notion of compensation in MCDM, European Journal of Operational Research 26 (1985), no. 1, 150-160.

[2] W. H. Bovey and A. Hede, Resistance to organizational change: the role of cognitive and affective processes, Leadership \& Organization Development Journal 22 (2001), no. 8, 372-382.

[3] D. Coghlan, A person-centred approach to dealing with resistance to change, Leadership \& Organization Development Journal 14 (1993), no. 4, 10-14.

[4] Y. Collette and P. Siarry, Multiobjective Optimization: Principles and Cases Studies, Decision Engineering, Springer, New York, 2003.

[5] J. Hugonnard and B. Roy, Le plan d'extension du métro en banlieue parisienne, un cas type de l'analyse multicritère, Les Cahiers Scientifiques de la Revue Transports 6 (1982), 77-108.

[6] C. L. Hwang and K. Yoon, Multiple Attribute Decision Making. Methods and Applications, Lecture Notes in Economics and Mathematical Systems, vol. 186, Springer, Berlin, 1981.

[7] A. Kangas, J. Kangas, and J. Pykäläinen, Outranking methods as tools in strategic natural resources planning, Silva Fennica 35 (2001), no. 2, 215-227.

[8] R. L. Keeney and H. Raiffa, Decisions with Multiple Objectives: Preferences and Value Tradeoffs, John Wiley \& Sons, New York, 1976.

[9] A. S. Milani and A. Shanian, A decision-based approach for measuring human behavioral resistance to organizational change in strategic planning, submitted to Mathematical and Computer Modelling.

[10] B. Roy, Classement et choix en présence de points de vue multiples (la méthode ELECTRE), Revue Française d'Informatique et de Recherche Opérationnelle 8 (1968), 57-75.

[11] __ Electre III: un algorithme de classements fondé sur une représentation floue des préférences en présence de critères multiples, Cahiers du Centre d'Études de Recherche Opérationnelle 20 (1978), no. 1, 3-24.

[12] __ Multicriteria Methodology for Decision Aiding, Kluwer Academic, Dordrecht, 1996.

[13] B. Roy and P. Bertier, La méthode ELECTRE II, Note de Travail 142, SEMA-METRA Metra International, Paris, 1971.

[14] B. Roy and D. Bouyssou, Aide Multicritère à la Décision: Méthodes et Cas, Economica, Paris, 1993.

[15] B. Roy and J. Skalka, ELECTRE IS: aspects méthodologiques et guide d'utilisation, Document du LAMSADE 30, Université Paris Dauphine, Paris, 1984.

[16] T. L. Saaty, The Analytic Hierarchy Process. Planning, Priority Setting, Resource Allocation, McGraw-Hill, New York, 1980.

[17] A. Schärlig, Pratiquer ELECTRE et PROMÉTHÉE: Un Complémenté à Décider sur Plusieurs Critères, Presses Polytechniques et Universitaires Romandes, Lausanne, 1996.

[18] A. van Delft and P. Nijkamp, A multi-objective decision model for regional development, environmental quality control and industrial land use, Papers in Regional Science 36 (1976), no. 1, $35-57$.

[19] R. Waldersee and A. Griffths, The changing face of organisational change, CCC Paper 065, Center for Corporate Change, Australian Graduate School of Management, the University of New South Wales, Sydney, 1997. 
[20] S. H. Zanakis, A. Solomon, N. Wishart, and S. Dublish, Multi-attribute decision making: a simulation comparison of select methods, European Journal of Operational Research 107 (1998), no. 3, $507-529$.

A. S. Milani: Department of Mechanical Engineering, Massachusetts Institute of Technology, 77 Massachusetts Avenue, Cambridge MA 02139, USA

E-mail address: milani@mit.edu

A. Shanian: Department of Management and Industrial Engineering, Industrial Management Institute, Jam-e-Jam, Vali-i-Asr, Tehran 1999915511, Iran

E-mail address: ali_shanian@hotmail.com

C. El-Lahham: Department of Mechanical Engineering, McGill University,

817 Sherbrooke Street West, Montreal, PQ, Canada H3A 2K6

E-mail address: christine.el-lahham@mail.mcgill.ca 


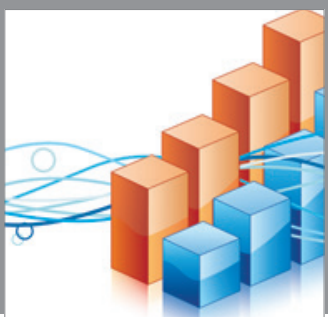

Advances in

Operations Research

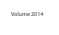

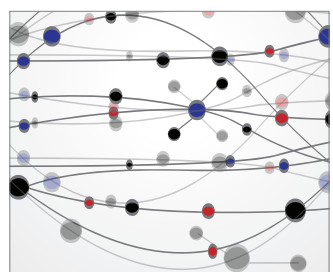

\section{The Scientific} World Journal
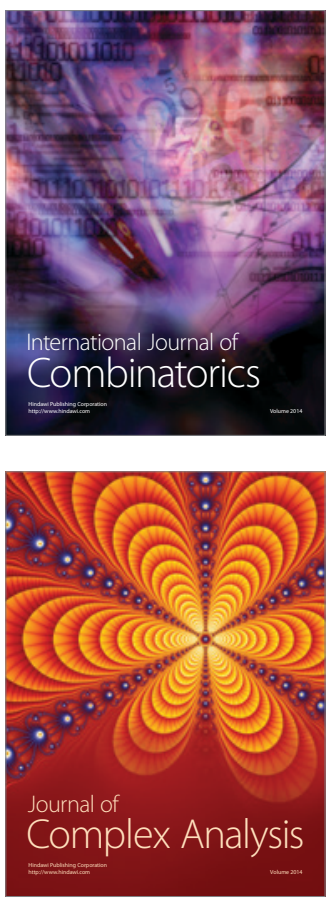

International Journal of

Mathematics and

Mathematical

Sciences
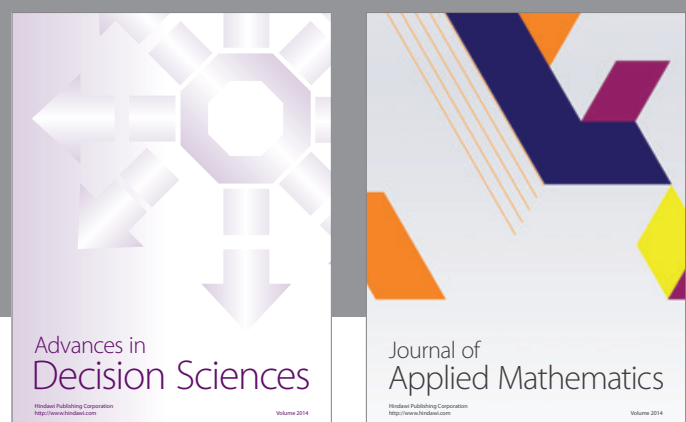

Journal of

Applied Mathematics
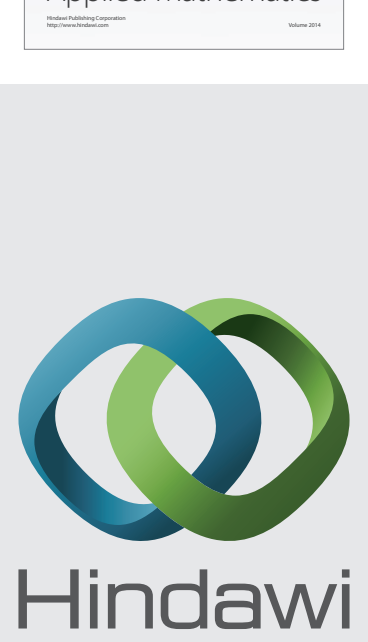

Submit your manuscripts at http://www.hindawi.com
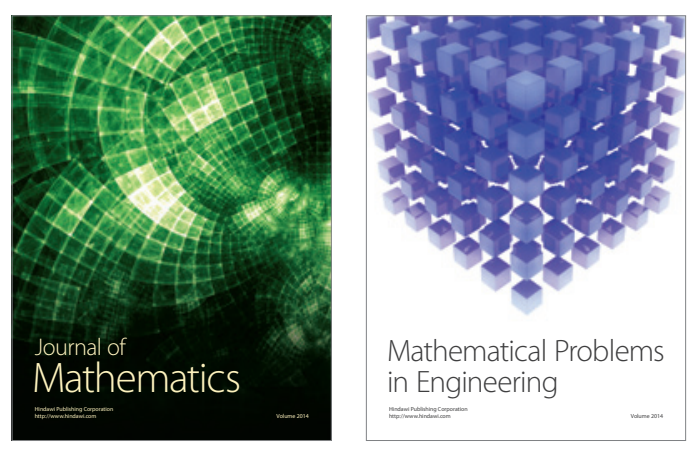

Mathematical Problems in Engineering
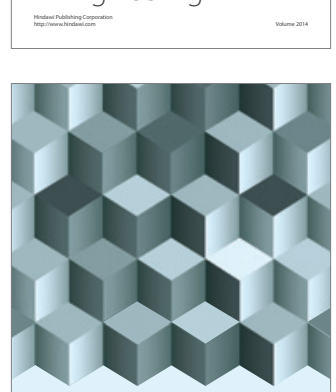

Journal of

Function Spaces
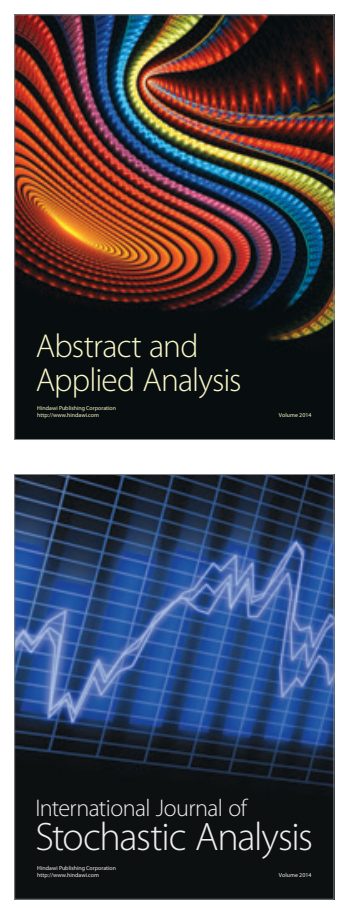

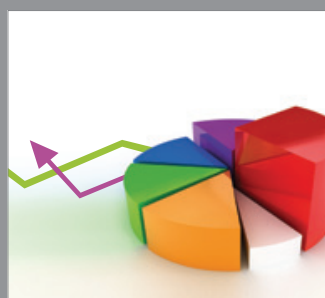

ournal of

Probability and Statistics

Promensencen
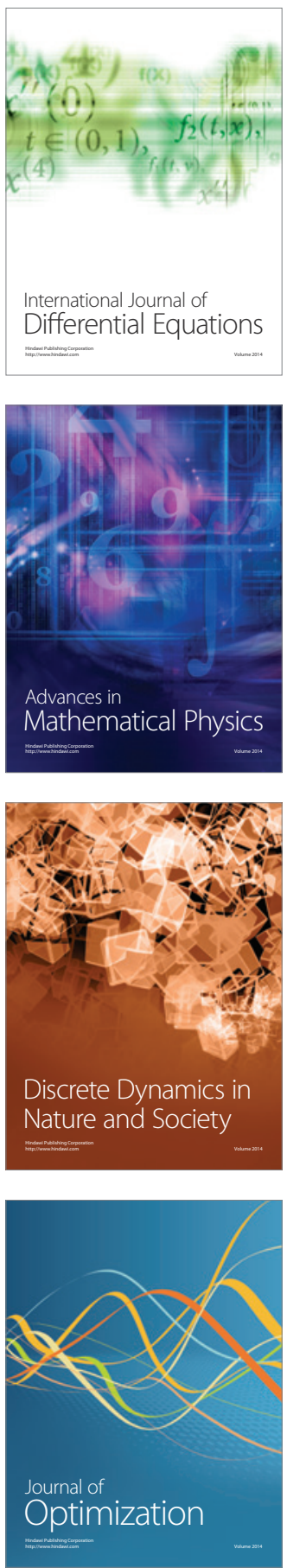